\title{
Political economy, esfandiyar's eye of development in Iran
}

\begin{abstract}
The close relationship between economy and politics in the world, especially in the underdeveloped or developing countries, is the radical factor in their laggardness. And, Iran is to not only be included in this circle but it also is amongst the countries wherein the political economy as the output of the economic and political strategies in the country is the most major factor giving rise to its laggardness. The decision-making elements have been classified in the areas of economy and politics in various levels. The most important of these areas is the decisions made by Iran's supreme leader in the area of domestic and foreign policies and confrontation with the economic corruption and not having a clearcut economic policy. Due to its subtle association with economy and politics and close relationship with other factors marking development in culture, social welfare, job security, minorities' security, gross domestic growth, the association between the nation and state and nation's attachment to the political structure has been acting quite unsuccessfully as caused by governance mechanisms. The investigation of the existing statistical indices in this regard in Iran's Statistics Website and succinct investigation of the corruptions in the files existent in the un-independent judicature branch and evident familial associations in the apex of the country's affairs, the investigation of the files on addiction, prostitution and tens of other cases all of which stemmed from Shiite-driven policies in the world and not related to the governing of the country causing the it to lag behind in development make it clear that the delinquency density and even faith and ethical infrastructures have been dragged towards very unfavorable indices. The main question is that how has politics influenced Iran's economy after the Islamic Revolution? Hypotheses:
\end{abstract}

A. The antagonistic spirits in Iran's leadership cadre has caused it economic challenges with the world;

B. Delegation of many authorities in the constitution to the leader has created a body of unaccountable power;

C. The absence of separate branches and lack of supervision by Guardians Council on all the decisions and options have caused the creation of a defective support cycle. The present study tries finding an answer to the main question and proving the hypotheses based on sufficient reasons.

Keywords: economy, development, politics, antagonism
Volume 4 Issue 3 - 2019

\author{
Javad Bahmani \\ Department of political anthropology, Islamic Azad University, \\ Iran
}

Correspondence: Javad Bahmani, Department of political anthropology, Islamic Azad University, Iran,

Email javadbahmanistu@gmail.com

Received: April 12, 2019 | Published: June 27, 2019

\section{Introduction}

In scientific principles and practical application arenas, the overlap of the economy and politics and sociology in a way or another in many of the cases is acceptable. For example, if it is found in a political approach towards power that the governance is possessed by an ideology-oriented oligarchy, the output, in sociological terms, would be elaboration of ideological values for the people and attraction of them towards the governing body. In economic area, the government shifts its selected approach unaccountably towards the society and adoption of policies for advancing its ideological approach in lieu of adopting a modern look at the stance of the governance and power in line with providing the citizens with a proper life and preserving the national interests within the framework of the society interests as well as other modern principles exercisable in a democratic governments. ${ }^{1}$

${ }^{1}$ Based on a story in Ferdawsi's Shahnameh (940), Esfandiyar's eye, equivalent in English to Achilles ankle, is the only weak point of a brazen-bodied human named Esfandiyar who was soaked in a liquid during his childhood to be kept safe of any impact and he closes his eyes when floating in the liquid as a result of which the liquid did not influence his eye and, such as it was, he was targeted of his eye by a two-headed arrow by Rostam, a mythical hero in Shahnameh and a protector of Iran against the enemies, following which he was defeated.
"If the economics is finally based on values, it cannot be defended as a completely scientific solution to the understanding of the social, political and economic institutions" (Barry Clark, adaptive political economy, p.466). This overlap navigates the known topics towards severe association of the economy with politics and sociology. This is a look the author believes in in the present study and assumes to give birth to political economy. However, every human school reserves itself a distinct economic approach whether be it liberalism, socialism etc. But, it has been shown now that the society and politics are continuously representing themselves in various forms, from developed to developing countries, in the face of each of these schools. Socialism repels the political elements of this perspective in the society and, now, contrary to liberalism, the free and unlimited economy and capitalism born of it have disordered the wealth distribution in society and world so intensely that such concepts as humanity and ethics have been forsaken in this area. ${ }^{1}$

Although the society and the thinkers show actions in this ground in line with the bridging of this deep hole that is deepening more, the very overlap of the economy, politics and society still persists. The accumulation of capital on the path to job and welfare creation and country's development is very useful when the humans come to 
the conclusion that they are using their own workforce to fatten a structure wherein nothing other than money is meaningful and makes sense because the companies are to constantly increase their profits to be able to strive in market competition hence they are forced to take advantage of any trick for the creation of consumers.

"The traditional scientists of sociology used to divide the society into separate areas, namely economy, politics and sociology, the dominance over which was claimed by them. Such distinctions, though being important, are misleading if attention is not paid to their overlaps and interdependencies. Therefore, it is more correct to describe these three areas as three different aspects of an interwoven network of systems". Such concepts made approaches to Iran be subjected to examination within a package comprised of economy, politics and society and the answers to the country's historical underdevelopment were rendered more transparent. As I have written in an article titled "the impact of culture on human being evolution", by political economy, I mean the effect of domestic and foreign policies and government's look at the subject of full-scale development and, subsequently, the effect of wealth distribution and the type of consumerism in a society dependent on modernism and tradition on a type of economy conceptualized as administration of the assets of a country and augmentation of them parallel to the improvement of people's lives. $^{2}$

I have stated in details that international regulations should be enacted in line with preservation of and movement towards ethicsorientation in this area so that prevention could be made from an uncontrolled status of capitalism. When one is free to the extent that s/ he does not harm the others' freedom, the amount of his or her personal capital should be also to the extent that, meanwhile providing him or her with an affluent life, it could be used of the remaining fraction in line with accumulation of wealth in favor of capitalist individuals and society with the stock distribution and administration being done by the elites selected by the civil society and such a type of capitalism should not cause indigence to the individuals in the other communities and countries. This might be termed as cosmopolitanism but, in fact, it pertains to the current situation of every individual and every country guided by capitalism that gives more value to money in the political power, delineates travel lines for the civil society and directs the society towards a power-oriented path using various media. This essential point has also been accepted that capital causes its accumulation on the path to production, scientific growth, lessening of poverty and any other positive point thereof. It is a problem that the governments have failed to overcome in the course of history, especially in Iran wherein the oil and renter state have left a sorry history of development and economic growth behind.

\section{Absorption of generative capital in Iran}

Based on what was mentioned and considering the inauspicious standpoints of Iran's society and politics in regard of investment risk due to the economy complicacies, the investors, both domestic and foreign, prefer venturing their capitals in spots featuring more political stability. The most primitive assessment by any investor in any region is the capital security as a subsequence to the political stability and existence of freedom and democracy in the path towards stabilization of the current trends of the government in the country and/or optimization of thereof within the framework of public wants. All of the political approaches originate under such circumstances from an internal comfort of the people as the possessors of the country. Such a situation is capable of creating fluctuations and chaos and illegality would not infiltrate therein. It might be due to the same reason that a group of thinkers describe development as essentially meaning freedom of expression. In Pahlavi system during the era of which the oil prices were in their peak, Muhammad Reza Shah decided to import technology to the country and, of course, such investments were either made by the government or by the individuals closely affiliated to the system in the form of loans. In such a state, the blossoming of the investment as the generator of economic move parallel to job creation and elevation of gross domestic income was losing its real stance in such a way that the investors fled after the victory of Islamic Revolution and whatever had been left in the area of the state investment was shattered. Shah would have not brought such a destiny for himself and the country if, at the same time with making moves towards importing technology and industry, he had attempted to open the paths of development such as political freedoms, distancing away from the governmental culture and creation of factions and political parties with diverse thoughts. This is the road that Islamic Republic has unfortunately more intensely stepped on and it is distancing away from the countries in possession of technology and closing in with such countries as china and Russia which do not refrain from imposing any tyranny on Iran on their path towards economic and industrial transactions with Iran to safeguard their own interests. Some examples are Bushehr's nuclear power plant that the Russia kept Iran busy with the construction thereof for a long period of time or the selling of the various sorts of Chinese raunchy goods to Iran due to its lack of ability for buying them from other countries in dollar and the boycott of Iran's banks as a result of which the world banks withdraw from cooperating with Iran due to the international embargoes followed by unilateral embargoes by the US in various areas, including banking, after BARJAM was signed during Barack Obama's presidency and then an even more intensified pursue of them by Trump following the lead of Obama at least up to the time of writing this text, to wit the second month of 2018 . $^{3}$

\section{Is Iran ready to change its political approach?}

Can it be expected that the economic pressure on the people and the hindrances to the country's development result in a change of approach by the government of the Islamic Republic in favor of the improvement of the economic conditions and people's status. So far, particularly after the war imposed by Iraq on Iran and the great many of the damages it caused to the country's infrastructures and economic interests, the country's foreign policy has been formed based on preservation of its ideological structure and it does not lend itself to any rotation. It is even so that the reformists supporting the existence of the system have not been capable of taking any measures in line with the improvement of the essential international relations of the country and open-door policies from inside the country. In return, they have been captured of a large number of them and their leader has been placed in siege. The current political system is administrated within the framework of supreme leader's ideas based on the constitution and it practically approves the existence of the people for the solidification of its ideological approach to Islam and it does not come to terms with any other steps beyond it unless it is envisaged too late in this temporal cross-section. Riots occurred in Iran during the past month that were quickly dragged to over eighty cities but, in opposite, the government only started suppressing them. If these movements do not receive an answer they deserve and the people constantly find themselves in a worse situation, it is not clear when a pervasive fire would flare out from under the ashes and this might be unbeneficial to the country. According to the unfortunate situation of the Middle East, a definitive change in the approaches for the calm correction of the affairs is deemed probable. Political 
governance means military forces and the leader and his advisors who have not so far accepted negotiation in any step. When the leader of the reformists, Ayatullah Khatami, spoke of national reconciliation, his highness said in a humiliating statement that when did the people break apart from one another. In a speech for New Year arrival in April, 2018, his highness asserted with full strength that there is freedom in Iran and it is based on this same freedom that the opponents take measures against government. His highness also pointed out that nobody has so far been sentenced to imprisonment and put under pressure for perpetration of such a crime as opposing the government. Of course, in an investigation of the judicial files of a large number of journalists or weblog writers or social and human rights activists and tens of political or quasi-political activities, the readers can figure out how many of the intellectuals of the country have been sentenced to incarceration for expressing their discrepancies with the government. The reformists are still beating on the drum of keeping the system and reforming now after elapse of twenty years since reformation was begun while their leaders like Khatami or Musavi or Rahnavard or Karrubi have now been under house custody for more than six years or prohibited from getting present in various gatherings or banned of their pictures being shown in newspapers and on TV. None of these behaviors can mean toleration and acceptance of talks and moving in the direction of what the people want in politics. The government's wish for everything and its use of Iran's huge wealth in line with showcasing itself as the Shiites' savior in Iran and in the other countries has caused the people's political and economic situation to become really painful and distressed. There are 13 million laborers for whom the minimum salary has been set at one million and two hundred thousand tomans in 2018. Now, adding their families to this group, how can they earn a living while the minimum expenditures have been calculated to be equal to two million and eight hundred thousand tomans in the country's statistics website. This is while during the ending months of 2017, workers and laborers participated in many strikes and protests to claim the salaries they have not been paid for several months. Renting via gaining access to the information and taking part in the power structure have made corruption infiltrate into the smallest bureaucratic bases of the country. ${ }^{4}$

\section{Can such a situation persist?}

Considering the various political patterns and pre- and postmodern histories (that of course, do not offer one single formula for all of the countries with different traditions and cultures), it can be inferred that the countries' political history does not reconcile with such a governor. The continuation of this method and claiming everything in the economic and political areas are still carried on, especially in Iran that the oldness of culture and wave of knowledge growth are quite charming, whereas in the current global relations and investment absorption for the economic growth, there is required total dependency between the foreign and domestic policy and international relations of the country and the economic status thereof. The selection of any growth and development school preliminarily needs political stability and playing an effective role in the global tranquility so that the domestic and foreign investments could be provided through making plans in line with equipping the infrastructures, dismissal of the industries' worn-outs and job creation along with which movement could be made on the path towards full-scale cultural, welfare, instructional development, civil society growth, supervision on the power by the people and keeping it accountable for its being aligned with a path directed at the people's wants. But, under the current conditions of economy and policy, as the foundations of political economy, severe problems have come about due to the government's behaviors in lack of taking the general public's developmental wants into consideration.

The present study has attempted to consider capital as whatever the thing that can be converted to a source of development in the country. It is what has been described by De Sutto as insufficient capital and turning it into working capital. This grounding is set by the thoughts and ideas and talents of the society members and it gives rise to capitalism in a society with competition equality and existence of identical facilities for everyone in offering their own intellectual accomplishments and making investments accordingly. So far, the mankind has not found conditions better than capitalism and democracy existing therein for making full-scale development. ${ }^{5}$

\section{Conclusion}

Islamic government in Iran should either give up to a practical balance in its behaviour and admit conditions posed by the US and sit at negotiation table, which is a contradiction to all the ideological principles it has leaning on, or it has to be prepared for more extensive riots in the country and/or, in a worst case, face a devastative military measure due to its great many of interventions in various countries as allies of Israel and the US. The most civilized method is delegation of power to the ones who are accepted by the people following which a secular religious law should be enacted for the country so that the country could be set free of administration based on the traditional jurisprudence of Qom's seminary.

\section{Acknowledgments}

None.

\section{Conflicts of interest}

Author declares that there is no conflict of interest.

\section{References}

1. Nazeri Mehrdad. Development sociology with an approach towards resources. $2^{\text {nd }}$ ed. Rouzaneh; 2016.

2. De Sutto Hernando. Secret of capital. $7^{\text {th }}$ ed. Fereidun Tafazoli, Ney; 2016.

3. Sean Amarthia. Development means freedom. Muhammad Sa'eid Nouri, Ney; 2017.

4. Opello Walter C. Nation-state and global system. Parviz Dalirpour, Kavir; 2010 .

5. Homayun Katouziyan, Muhammad Ali. Contradiction between the state and the nation: theory of history and politics in Iran. $4^{\text {th }}$ ed. Ney; 2006. 